\title{
Prevention, Control and Monitoring of Fires in the Brazilian Cerrado
}

\author{
Lara Steil $^{I^{*}}$, Luciana de Oliveira Rosa Machado ${ }^{2}$, Mariana Senra de Oliveira ${ }^{1}$, Aline Freire de Miranda \\ Cavalcante $^{l}$
}

\author{
${ }^{1}$ Brazilian National Center for Prevention and Fighting Fires (Prevfogo) - Brazilian Institute for \\ Environment and Renewable Natural Resources (Ibama), Brasilia, Brazil \\ ${ }^{2}$ Brazilian Ministry of Environment (MMA), Brasilia, Brazil \\ *Contact email:: lara.steil@ibama.gov.br
}

\begin{abstract}
The Brazilian Cerrado covers $24 \%$ of the national territory. It is home of a diversity of phytophysiognomies that shelters about $5 \%$ of the world's biodiversity. The Cerrado is an ecosystem that have been shaped by a long history of fire, caused by lightning or human ignition. The people who lived and still live there have used fire for thousands of years influencing the ecosystem. In the scenario of climate change and landuse change that modify the fire regime, leading to increase intense degradation processes, the Brazilian government has been supporting initiatives for conservation and sustainable use of the biome. In 2011, the implementation of the Brazil-Germany Cooperation Project for prevention, control and monitoring of fire in the Cerrado, called as Cerrado-Jalapão Project, began. Federal and state government agencies and the local communities were involved in the project. The focus of Prevfogo/Ibama in the project was the indigenous lands in the states of Tocantins and Mato Grosso. The activities included (1) acquisition of equipment and vehicles adapted for fighting fire operations; (2) environmental education processes; (3) training and implementation of the integrated fire management (IFM) approach. As results of the project: the response capacity of Prevfogo to fire events was improved; a better efficiency and effectiveness of the brigades were achieved; a closer cooperation with the local communities was developed, increasing the local capacity for fire management. Three indigenous lands were initially pilot areas for the IFM approach. Nowadays, IFM is applied in 26 indigenous lands, including 43 ethnic groups and an area of circa 10 million hectares with preventive and protective actions against fire damages. The Cerrado-Jalapão Project has also made a very valuable contribution to the paradigm shift underway in the country: from a zero-fire policy to a policy considering fire as a management tool. A bill that institutes the National Policy for Integrated Fire Management (bill number 11.276/2018) is under way in the National Congress. The document highlights the potential contribution of international cooperation in the improvement of efficiency and effectiveness of national strategies.
\end{abstract}

Keywords: Cerrado, savannah, integrated fire management, indigenous land, public policies. 